\title{
Desempenho e qualidade dos ovos de poedeiras comerciais alimentadas com rações contendo farelo de coco tratado ou não com antioxidante
}

\author{
Irani Ribeiro Vieira Lopes ${ }^{1}$, Ednardo Rodrigues Freitas ${ }^{2}$, Janice Ribeiro Lima ${ }^{3}$, José Lopes \\ Viana Neto ${ }^{4}$, Roseane Madeira Bezerra ${ }^{5}$, Raffaella Castro Lima ${ }^{5}$
}

1 Programa de Doutorado Integrado em Zootecnia - PDIZ/CCA/UFC.

2 Departamento de Zootecnia - CCA/UFC.

${ }^{3}$ EMBRAPA - Agroindústria Tropical, Fortaleza - CE.

${ }^{4}$ ADAGRI - Canindé - CE.

${ }^{5}$ Curso de Graduação em Zootecnia - DZ/CCA/UFC.

RESUMO - Este experimento foi conduzido para avaliar a estabilidade oxidativa do farelo de coco (FC) tratado ou não com butil-hidroxitolueno (BHT) e armazenado por 35 dias e estudar o efeito de rações contendo esse ingrediente sobre o desempenho e a qualidade do ovo de poedeiras. Um lote de $200 \mathrm{~kg}$ de farelo de coco foi dividido em cinco partes: uma foi armazenada sem a adição de antioxidante e as demais tratadas com 500 ppm de BHT nos dias 0, 7, 14 e 21. A estabilidade oxidativa do farelo de coco foi acompanhada por meio dos índices de acidez e de peróxidos, determinados semanalmente. Após 35 dias de armazenamento, $10 \%$ de farelo de coco tratado e não tratado com BHT nos diferentes tempos de armazenamento foi usado na formulação de rações isonutrientes para poedeiras comerciais. Foram utilizadas 180 poedeiras da linhagem Hisex White, distribuídas ao acaso em 5 tratamentos e 6 repetições de 6 aves cada. Os índices de acidez e de peróxidos do farelo de coco armazenado com ou sem BHT aumentaram com o tempo de armazenamento. Contudo, os tratamentos não afetaram o desempenho nem a qualidade dos ovos das aves. O farelo de coco armazenado por 35 dias sem antioxidante, embora sofra oxidação, pode ser usado em níveis de até $10 \%$ na ração para poedeiras comerciais.

Palavras-chave: BHT, índice de peróxidos, produção de ovos, unidades Haugh

\section{Performance and egg quality of laying hens fed diets containing coconut meal treated with and without antioxidant}

\begin{abstract}
This experiment was conducted to evaluate the oxidative stability of coconut meal treated with or without butylated hydroxytoluene (BHT) at different storage times and the effect of diets containing this ingredient on laying hens' performance and egg quality. A 200-kg batch of freshly produced coconut meal was divided into five equal portions. One portion was stored without BHT and the others were treated with BHT at zero, 7, 14 and 21 days. The oxidative stability of coconut meal was measured by the acidity index and peroxide index determined weekly. At the end of the 35-day storage time, this ingredient was used in the formulation of diets for laying hen. One hundred and eighty Hisex White laying hens were randomly distributed among five treatments with six repetitions of six birds each. The acidity index and peroxide index of coconut meal treated with or without BHT at different periods of time increased with storage time. Nevertheless, treatments did not affect laying hens' performance or egg quality. Coconut meal stored for 35 days, although showing lipid peroxidation, can be included at $10 \%$ level in the diet for commercial poultry.
\end{abstract}

Key Words: BHT, egg production, Haugh units, peroxide index

\section{Introdução}

O aproveitamento de subprodutos da agroindústria regional inadequados à alimentação do homem é uma alternativa para melhorar a oferta de alimentos que possam reduzir os custos de produção sem afetar o desempenho das aves, principalmente em criatórios avícolas de pequeno e médio porte.
O endosperma do coco maduro (copra), principal produto comercial obtido do coco, é usado para a extração do óleo. O farelo de coco, resíduo resultante da extração do óleo por meio de solventes ou por prensagem mecânica vem sendo incorporado à alimentação de frangos (Bastos et al., 2007) e poedeiras (Lima et al., 2007).

Mesmo após a extração do óleo, o farelo de coco ainda apresenta certo teor de gordura e está propenso a 
desenvolver rancidez oxidativa. Os radicais livres originados durante o processo oxidativo se propagam destruindo os ácidos graxos essenciais, as proteínas, as vitaminas lipossolúveis e os carotenoides dos alimentos (Leeson \& Summers, 2001). Nos casos em que esta destruição é mais severa, as aves podem apresentar sintomas de doenças carenciais, como encefalomalácia, diástase exsudativa, distrofia muscular, necrose dos tecidos em vários órgãos, além de redução na fertilidade e na eclodibilidade (Cabel et al., 1988). Na etapa final da oxidação, são formados vários compostos que alteram o sabor dos alimentos e têm efeitos tóxicos ao organismo (Wang et al., 1997).

Para neutralizar os efeitos deletérios dos radicais livres, são utilizados os antioxidantes, cuja função é preservar o alimento, retardando sua deterioração. A adição de antioxidante aos ingredientes ou às rações, além de evitar gastos com a suplementação de nutrientes especializados, destruídos durante o processo de peroxidação, também dá ao nutricionista a certeza de estar formulando rações mais próximas das exigências estabelecidas e que os nutrientes estarão disponíveis para os animais (Fischer et al., 2005). Entretanto, o tratamento do farelo de coco com antioxidante tem um custo adicional que poderá ser desfavorável à sua utilização na alimentação animal.

Esta pesquisa foi realizada com o objetivo de avaliar a estabilidade oxidativa do farelo de coco tratado ou não com antioxidante em diferentes tempos e armazenado por 35 dias para estudo do efeito de seu fornecimento nas rações sobre o desempenho produtivo e a qualidade dos ovos de poedeiras comerciais.

\section{Material e Métodos}

Um lote de $200 \mathrm{~kg}$ de farelo de coco foi adquirido logo após sua produção. No dia de sua chegada à Fábrica de Ração da Universidade Federal do Ceará (UFC), todo o farelo foi triturado e misturado. Concluída a homogeneização do material, foram coletadas duas amostras do farelo de coco: uma foi encaminhada ao Laboratório de Nutrição Animal para análise de composição química e a outra, levada para determinação dos índices de acidez e de peroxidação.

Após a coleta das amostras, o lote foi dividido em cinco porções de $40 \mathrm{~kg}$. No dia zero, uma porção foi armazenada sem adição de antioxidante (butil hidroxitolueno - BHT) e as demais foram tratadas com $20 \mathrm{~g}$ de BHT, equivalente a $500 \mathrm{ppm}$, nos dias 0, 7, 14 e 21. Os lotes de farelo de coco tratado e não tratado com BHT foram acondicionados em sacos de ráfia e estocados sobre tablado de madeira, em local coberto, seco, bem ventilado e fora do alcance da luz, durante o período de 35 dias.
Semanalmente, durante o armazenamento, foram coletadas amostras de todos os tratamentos de farelo de coco com o objetivo de monitorar os índices de acidez e de peroxidação do produto, determinados de acordo com as metodologias descritas na AOAC (1990).

Decorrido o tempo de estocagem, o farelo de coco tratado com BHT nos dias 0, 7, 14 e 21 e o farelo de coco não tratado foram utilizados para formular as rações das poedeiras.

Antes do experimento propriamente dito, as aves passaram por um período pré-experimental de 15 dias em que a produção diária foi controlada para identificação das aves que não estavam em postura. Ao final deste período, as aves em produção foram pesadas, separadas por faixa de média de peso e distribuídas uniformemente nas gaiolas, de modo que todas as repetições tivessem aves com pesos similares.

Foram utilizadas 180 poedeiras, da marca Hisex White, no segundo ciclo de postura, alojadas duas a duas em gaiolas de arame $(25 \times 40 \times 30 \mathrm{~cm})$, de acordo com os tratamentos. O delineamento utilizado foi o inteiramente casualizado, com cinco tratamentos e seis repetições, cada uma de seis aves.

Os valores de exigências nutricionais das poedeiras e de composição dos alimentos usados para formular as rações experimentais foram baseados nas tabelas de Rostagno et al. (2000). Para o farelo de coco, foram utilizados os dados descritos pela EMBRAPA (1991), os quais foram “ajustados” segundo as análises realizadas no Laboratório de Nutrição Animal da UFC. Essas análises, realizadas de acordo com as metodologias relatadas por Silva \& Queiroz (2002), apresentaram os seguintes resultados: $96,17 \%$ de matéria seca (MS); 25,09\% de proteína bruta (PB); 21,66\% de extrato etéreo (EE); 15,07\% de fibra bruta(FB); 23,77\% de fibra em detergente ácido (FDA); 59,29\% de fibra em detergente neutro (FDN); e 5.391 kcal de energia bruta (EB)/kg.

Os tratamentos consistiram de cinco rações isonutritivas (Tabela 1) contendo: farelo de coco sem adição de BHT (s/BHT); farelo de coco com adição de BHT no dia zero (BHT/0); farelo de coco com adição de BHT 7 dias após o armazenamento (BHT/7); farelo de coco com adição de BHT 14 dias após o armazenamento (BHT/14); e farelo de coco com adição de BHT 21 dias após o armazenamento (BHT/21).

O experimento teve duração de 63 dias, divididos em três períodos de 21 dias, durante os quais as aves receberam ração e água à vontade e um programa de luz com 16,5 horas de luz por dia. A temperatura e a umidade relativa média do ar no galpão foram registradas diariamente às $8 \mathrm{~h}$ e às $16 \mathrm{~h}$. 
Tabela 1 - Composição das rações experimentais

\begin{tabular}{|c|c|}
\hline Ingredientes & $\%$ \\
\hline Milho grão & 60,634 \\
\hline Soja farelo, $45 \%$ & 17,870 \\
\hline Coco farelo & 10,000 \\
\hline Calcário & 8,772 \\
\hline Fosfato monobicálcico & 1,388 \\
\hline Óleo de soja & 0,474 \\
\hline Sal comum & 0,368 \\
\hline Mistura vitamínica ${ }^{1}$ & 0,200 \\
\hline Mistura mineral ${ }^{2}$ & 0,100 \\
\hline $\mathrm{L}$-lisina $\mathrm{HCl}$ & 0,081 \\
\hline DL-metionina $99 \%$ & 0,078 \\
\hline Pigmento $^{3}$ & 0,025 \\
\hline ВНT & 0,010 \\
\hline Total & 100,000 \\
\hline \multicolumn{2}{|l|}{ Níveis nutricionais calculados } \\
\hline Energia metabolizável, kcal/kg & 2.750 \\
\hline Proteína bruta, \% & 16,00 \\
\hline Fibra bruta, \% & 3,59 \\
\hline Cálcio, \% & 3,80 \\
\hline Fósforo disponível, \% & 0,38 \\
\hline Fósforo total, \% & 0,59 \\
\hline Lisina, \% & 0,78 \\
\hline Metionina, \% & 0,33 \\
\hline Metionina + cistina, \% & 0,59 \\
\hline Treonina, \% & 0,59 \\
\hline Triptofano, \% & 0,17 \\
\hline Sódio, \% & 0,18 \\
\hline \multicolumn{2}{|c|}{$\begin{array}{l}{ }^{1} \text { Quantidade/kg do produto: vit. A - } 3.500 .000 \mathrm{UI} \text {; vit. D3 - } 750.000 \text { UI; vit. E - } \\
2.000 \mathrm{mg} \text {; vit. K3 - } 1.000 \mathrm{mg} \text {; vit. B1 - } 1.000 \mathrm{mg} \text {; vit. B2 - } 1.500 \mathrm{mg} \text {; vit. B12 - } \\
4.000 \mathrm{mcg} \text {; niacina - } 7.500 \mathrm{mg} \text {; pantotenato de cálcio - } 2.500 \mathrm{mg} \text {; selênio - } 150 \mathrm{mg} \text {; } \\
\text { cloreto de colina - } 250 \mathrm{~g} \text {; antioxidante - } 25 \text { g; veículo q.s.p. - } 1.000 \mathrm{~g} \text {. } \\
2 \text { Quantidade/kg do produto: manganês - } 65.000 \mathrm{mg} \text {; zinco - } 50.000 \mathrm{mg} \text {; ferro - } \\
50.000 \mathrm{mg} \text {; cobre - } 12.000 \mathrm{mg} \text {; iodo - } 1.000 \mathrm{mg} \text {; veículo q.s.p. - } 1.000 \mathrm{~g} \text {. } \\
{ }^{3} \text { SunRed }^{\circledR} \text {. }\end{array}$} \\
\hline
\end{tabular}

A quantidade de ração consumida em cada período de 21 dias foi determinada por meio da pesagem da ração fornecida e das sobras. O controle da produção foi realizado diariamente, por meio de registro do número de ovos coletados por gaiola e ao final de cada período, dividindo-se o total de ovos produzidos pelo número médio de aves de cada parcela, foi calculada a porcentagem de postura.

Uma vez por semana, sempre no mesmo horário, todos os ovos coletados foram armazenados à temperatura de $18{ }^{\circ} \mathrm{C}$, sendo pesados na manhã seguinte em balança eletrônica de precisão $0,01 \mathrm{~g}$, para determinação do peso médio do ovo. Os dados foram utilizados no cálculo da massa de ovos. A conversão alimentar foi expressa em gramas de ração consumida por gramas de massa de ovo produzida.

Para avaliar as características e a qualidade dos ovos, após a pesagem semanal, três ovos de cada repetição foram quebrados sobre uma superfície plana de vidro. Com o auxílio de um micrômetro digital, mediu-se a altura do albúmen, e por meio da relação logarítmica entre o peso do ovo (PO) e a altura do albúmen (A), determinou-se a unidade Haugh (UH).
A coloração da gema de cada ovo foi comparada utilizando-se o leque colorimétrico da Roche. As gemas foram pesadas individualmente e as cascas, depois de lavadas cuidadosamente em água corrente e postas para secar a sombra, em temperatura ambiente, por 48 horas, foram pesadas. A porcentagem de albúmen (\%A) foi obtida por diferença [100 - $(\% \mathrm{G}+\% \mathrm{C})]$.

As mortes ocorridas durante o experimento foram registradas. Ao término do período experimental, todas as aves foram pesadas.

As análises estatísticas dos dados foram realizadas por meio do Statistical Analyses System (SAS, 2000) utilizando-se o procedimento ANOVA. A comparação entre as médias foi realizada pelo teste Dunnett (5\% de probabilidade), considerando a ração contendo farelo de coco não tratado com antioxidante durante todo o período de armazenamento (s/BHT) como tratamento controle.

\section{Resultados e Discussão}

Durante o ensaio de desempenho das poedeiras, a temperatura média calculada no galpão foi de $28,75^{\circ} \mathrm{C}$, a média das mínimas de $28,10 \pm 1,24^{\circ} \mathrm{C}$ e a média das máximas de $29,40 \pm 1,92{ }^{\circ} \mathrm{C}$. No período, o valor médio da umidade relativa do ar foi de 78,0 $\pm 2,0 \%$.

A acidez inicial (2,026 meq $/ \mathrm{kg}$ ) observada no farelo de coco ao chegar à fábrica de ração e o aumento de mais de $65 \%$ no índice de acidez do farelo de coco armazenado por 35 dias (Tabela 2) podem ser explicados pela concentração de ácidos graxos livres provenientes da lipólise provocada por microrganismos na copra e/ou no farelo de coco durante o armazenamento. De acordo com Cornelius (1973), a copra in natura apresenta alto teor de umidade que favorece o desenvolvimento de fungos e de bactérias. Por sua vez, o crescimento desses microrganismos resulta na quebra de lipídios e consequente liberação de ácidos graxos, que, em concentrações elevadas, incrementam o nível de acidez no endosperma do coco maduro.

Aos 35 dias de armazenamento, o fato de oíndice de acidez do farelo tratado com BHT no dia zero (3,388 meq/100 g) ser próximo ao do farelo de coco não tratado (3,596 meq/100 g), assim como os valores de acidez do farelo tratado com BHT nos dias 7, 14 e 21 serem superiores ao do farelo de coco não tratado, pode ser indicativo de que os antioxidantes não tenham ação sobre esse tipo de rancidez, visto que esta decorre da ação microbiana (Silva et al., 1990).

Na literatura são encontrados relatos da eficiência dos antioxidantes em controlar o processo oxidativo dos lipídios (Robey \& Shermer, 1994). Entretanto, nesta pesquisa, os 
índices de peróxidos (IP) aumentaram gradativamente com o decorrer do tempo de armazenamento (Tabela 2), tanto nos farelos tratados como naquele não tratado com BHT, valores bastante próximos entre si aos 35 dias de armazenamento. Resultados semelhantes foram descritos por Wang et al. (1997), que não observaram diferenças no índice de peróxidos da gordura rancificada ou não com a adição de antioxidante (ETQ).

Incrementos nos índices de peróxidos com o avanço do período de estocagem também foram observados por Silva et al. (1990) no farelo de arroz integral, por Mcgeachin et al. (1992) no óleo vegetal, por Racanicci et al. (2000) na farinha de carne e ossos e por Fischer et al. (2005) no milho triturado, embora os pesquisadores tenham relatado que a inclusão do antioxidante retardou o processo de peroxidação.

Por outro lado, Hussein \& Kratzer (1982), utilizando EDTA para controlar a oxidação do farelo de arroz armazenado por três meses, constataram que este antioxidante interrompeu o processo oxidativo quando incorporado ao farelo no início do armazenamento. No entanto, o EDTA não teve nenhum efeito sobre o farelo de arroz em processo avançado de peroxidação.

A necessidade de se adicionar o antioxidante aos ingredientes antes de ter início a lipoperoxidação foi relatada por Leeson \& Summers (2001). Segundo esses autores, uma vez iniciado, o processo não pode ser revertido e as substâncias formadas permanecem no produto. Esta situação parece explicar os resultados obtidos nesta pesquisa, em que o BHT foi incorporado ao farelo de coco que apresentava indícios de peroxidação lipídica $(1,372 \mathrm{meq} / \mathrm{kg})$ quando chegou à fábrica de ração (Tabela 2$)$.

Não houve influência $(\mathrm{P}>0,05)$ das rações contendo farelo de coco tratado ou não com antioxidante em diferentes tempos de armazenamento sobre as variáveis de consumo de ração, porcentagem de postura, peso do ovo, massa de ovo e conversão alimentar (Tabela 3).

Galinhas poedeiras, assim como outras aves, ajustam seu consumo de alimento pelos níveis energéticos da ração (Leeson, 1996; Grobas et al., 2001). A lipoperoxidação reduz o teor de ácidos graxos da fração lipídica do alimento ou da ração (Engberg et al., 1996), o que pode resultar em diminuição nos valores de EMA e EMAn (Silva et al., 1990; Leeson \& Summers, 2001) e aumento no consumo de ração pelas aves. Como as rações experimentais foram isonutritivas (Tabela 1 ), pode-se afirmar que seus baixos valores de rancidez hidrolítica $(\leq 0,389 \mathrm{meq} / 100 \mathrm{~g})$ e oxidativa $(\leq 0,322 \mathrm{meq} / \mathrm{kg})$ não afetaram o aproveitamento dos nutrientes, pois o consumo não variou $(\mathrm{P}>0,05)$ entre os tratamentos. Segundo Cabel et al. (1988), o nível máximo tolerável de IP na ração para aves é de $4 \mathrm{meq} / \mathrm{kg}$, valor superior ao determinado neste trabalho (IP $\leq 0,322 \mathrm{meq} / \mathrm{kg}$ ).

Tabela 2 - Índices de acidez e de peróxidos do farelo de coco, tratado ou não com BHT, em diferentes tempos de armazenamento

\begin{tabular}{lccccc}
\hline Tratamentos & \multicolumn{5}{c}{ Tempo de armazenamento (dias) } \\
\cline { 2 - 6 } & 0 & 7 & 14 & 21 & 28 \\
\hline & & & Índices de acidez (meq/100g) & 35 \\
FC sem BHT & 2,026 & 2,431 & 2,835 & 2,785 & 3,696 \\
FC com adição de BHT/0 & 2,026 & 2,125 & 1,772 & 1,312 & 2,429 \\
FC com adição de BHT/7 & 2,026 & 2,431 & 2,531 & 2,529 & 3,340 \\
FC com adição de BHT/14 & 2,026 & 2,431 & 2,835 & 2,278 & 3,798 \\
FC com adição de BHT/21 & 2,026 & 2,431 & 2,835 & 2,785 & 3,834 \\
& & & Índices de peróxidos (meq/kg) & 3,799 \\
FC sem BHT & 1,372 & 1,756 & 2,134 & 2,214 & 3,065 \\
FC com adição de BHT/0 & 1,372 & 1,454 & 2,424 & 2,822 & 3,222 \\
FC com adição de BHT/7 & 1,372 & 1,756 & 2,233 & 2,529 & 3,044 \\
FC com adição de BHT/14 & 1,372 & 1,756 & 2,134 & 2,227 & 3,077 \\
FC com adição de BHT/21 & 1,372 & 1,756 & 2,134 & 2,214 & 2,987 \\
M
\end{tabular}

Médias diferem $(\mathrm{P}<0,05)$ pelo teste Dunnett.

Tabela 3 - Desempenho de poedeiras alimentadas com rações contendo farelo de coco tratado ou não com BHT durante o armazenamento

\begin{tabular}{lcccccc}
\hline Variável & \multicolumn{4}{c}{ Tempo de } & armazenamento (dias) & \multicolumn{2}{c}{ Média } & \multicolumn{2}{c}{ CV (\%) } \\
\cline { 2 - 5 } & Sem BHT & BHT/0 & BHT/7 & BHT/14 & BHT/21 \\
\hline Consumo de ração (g/ave/dia) & 101,09 & 101,08 & 98,57 & 98,10 & 100,07 & 99,78 \\
Percentagem de postura (\%) & 85,39 & 84,14 & 84,18 & 84,44 & 82,32 & 84,09 \\
Peso do ovo (g) & 63,66 & 65,70 & 64,63 & 62,61 & 64,70 & 64,26 \\
Massa de ovo (g/ave/dia) & 54,37 & 55,29 & 54,43 & 52,83 & 53,31 & 54,05 \\
Conversão alimentar & 1,86 & 1,83 & 1,81 & 1,86 & 1,88 & 1,85 \\
\hline
\end{tabular}

Médias diferem $(\mathrm{P}<0,05)$ pelo teste Dunnett. $\mathrm{CV}=$ Coeficiente de variação. 
Por outro lado, a quantidade de alimento ingerido voluntariamente está relacionada à palatabilidade da ração. Algumas vezes, os ácidos graxos livres gerados durante a hidrólise da gordura (Leeson \& Summers, 2001) e as substâncias formadas durante o processo de lipoperoxidação podem promover odor e sabor desagradáveis ao alimento, diminuindo a palatabilidade da ração e piorando o consumo pelas aves (Bermudez et al., 2002). Nesta pesquisa, o nível de acidez e os metabólitos formados não foram suficientes para afetar $(\mathrm{P}>0,05)$ a palatabilidade das rações testadas, uma vez que não houve diferença na quantidade de alimento ingerido pelas aves (Tabela 3).

Outro fator que pode exercer influência sobre a ingestão de alimentos é o nível de fibra bruta da ração. De acordo com Panigrahi (1989), o alto teor de fibra presente no farelo de coco, além de alterar a densidade da ração, tem alta capacidade relativa de absorção de água, que associadas, contribuem para a redução no consumo, devido ao volume ocupado por esse material no trato digestório. Como todas as rações experimentais tiveram o mesmo percentual de inclusão de farelo de coco, o teor de fibra não variou entre os tratamentos e, portanto, não afetou o consumo (Tabela 3).

De forma semelhante, não foi encontrado efeito $(\mathrm{P}>0,05)$ da incorporação de BHT ao farelo de coco no consumo de ração (Tabela 3). O fato de não ter sido observada diferença $(\mathrm{P}>0,05)$ na quantidade de ovos produzidos entre as aves que receberam rações contendo farelo de coco, tratado ou não com BHT durante o armazenamento, pode ser atribuído à ingestão de rações isonutritivas, já que o consumo não variou (Tabela 3).

Leeson \& Summers (2001) destacam a importância do ácido linoleico para máxima produção de ovos, visto o alto percentual deste ácido na gema do ovo. Entretanto, Meluzzi et al. (2000) e Pita et al. (2004) não observaram diferenças na porcentagem de postura entre as aves que receberam rações enriquecidas com AGPI suplementadas com $\alpha$-tocoferil acetato e as do grupo em que estas rações não foram suplementadas. Até mesmo o consumo de ração contendo farelo de arroz rancificado (IP $\leq 28,25 \mathrm{meq} / \mathrm{kg}$ de ração), armazenado sem ou com antioxidante (BHT e ETQ), não foi capaz de afetar a produção de poedeiras (Silva et al., 1990). Também nesta pesquisa, a ingestão de rações contendo farelo de coco (IP $\leq 0,322 \mathrm{meq} / \mathrm{kg}$ de ração) tratado ou não com BHT durante o armazenamento não alterou a porcentagem de postura das aves (Tabela 3).

Autores como Leeson (1996) e Leeson \& Summers (2001) descreveram que o peso do ovo é fortemente influenciado pelo consumo adequado de proteína e aminoácidos, principalmente metionina. Como neste experimento as rações utilizadas foram isoproteicas e isoaminoacídicas e formuladas para atender às exigências nutricionais de poedeiras em fase de produção, e considerando ainda que não houve variação no consumo de ração entre as aves, era esperado que o peso do ovo não diferisse em função dos tratamentos.

Também tem sido observado que o conteúdo de ácido linoleico na ração afeta o tamanho e, consequentemente, o peso do ovo (Leeson \& Summers, 2001). Isso acontece porque este ácido não é sintetizado pelo organismo das aves e seu suprimento depende exclusivamente de fonte exógena. Dessa forma, a rancidez oxidativa dos AGPI da fração lipídica da ração pode reduzir consideravelmente o conteúdo de ácido linoleico da ração e prejudicar o peso dos ovos.

Nesse contexto, parece que o nível de peroxidação no farelo de coco armazenado durante 35 dias com ou sem BHT não foi capaz de promover alterações na fração lipídica das rações suficientes para influenciar no tamanho dos ovos, visto que os ovos produzidos pelas aves dos diferentes tratamentos apresentaram $(\mathrm{P}>0,05)$ pesos semelhantes (Tabela 3). Esses resultados corroboram os obtidos por Silva et al. (1990) e Bermudez et al. (2002), que não verificaram efeito significativo do nível de peroxidação do farelo de arroz integral e do milho triturado, respectivamente, sobre o peso dos ovos de poedeiras comerciais.

A suplementação de rações ricas em AGPI com vitamina E não promoveu aumento no peso dos ovos das aves deste grupo em relação ao daquelas cujas rações não foram suplementadas com este antioxidante natural (Meluzzi et al., 2000; Pita et al., 2004).

De forma semelhante, a incorporação de ETQ e/ou BHT ao milho triturado (Silva et al., 1990) e ao farelo de arroz integral (Bermudez et al., 2002), ambos rancificados, não resultou em ovos mais pesados. Ausência de efeito de BHT adicionado ao farelo de coco sobre o peso dos ovos também foi constatada também nesta pesquisa.

Na massa de ovo (produção $\times$ peso médio dos ovos), o efeito do número de ovos parece ser predominante (Leeson, 1996), de modo que os valores desta variável aumentam de acordo com a porcentagem de postura das aves (Lima Neto et al., 2007). Como a inclusão de $10 \%$ de farelo de coco tratado ou não com BHT em diferentes tempos de armazenamento na ração não influenciou $(\mathrm{P}>0,05)$ o peso e a produção de ovos, a massa de ovo (g/ave/dia) também não foi afetada (Tabela 3).

A conversão alimentar (g de ração/g de ovo), calculada com base no consumo de ração e na massa de ovo, não diferiu $(\mathrm{P}>0,05)$ entre os grupos de aves que receberam as rações contendo farelo de coco tratado com BHT em diferentes tempos de armazenamento e aquele em que o farelo não foi tratado (Tabela 3). Esse resultado foi reflexo 
da ausência de variação na quantidade de alimento ingerido e na massa de ovo produzida em cada período.

A qualidade dos ovos medida pelas unidades Haugh, a porcentagem de gema, de casca e de albúmen e coloração da gema não foram afetadas $(\mathrm{P}>0,05)$ pelas rações contendo farelo de coco tratado ou não com BHT durante o armazenamento (Tabela 4).

A qualidade interna do ovo pode ser avaliada com base no albúmen, na gema, na câmara de ar e pela presença de manchas de sangue ou de carne. As análises realizadas no albúmen, além de serem facilmente executadas, fornecem uma boa ideia da qualidade geral do ovo. A determinação da unidade Haugh (UH) é a principal forma de medir as alterações no albúmen (Mano et al., 2007). Ovos de boa qualidade apresentam índices acima de 72 UH. Nesta pesquisa, os tratamentos não afetaram $(\mathrm{P}>0,05)$ as UH dos ovos avaliados, pois todos os valores foram acima de 84 (Tabela 4).

O albúmen é constituído principalmente de água (87 a $89 \%$ ) e proteína (9,5 a 11,5\%), componentes que dificilmente são modificados em função da ração (Grobas \& Mateos, 1996).

Devido à ausência de lipídios neste componente do ovo, Grobas et al. (2001) constataram que alterações nas fontes e níveis de gordura nas rações, assim como o consumo de ração rancificada (Silva et al., 1990), não afetam a composição e a qualidade do albúmen, desde que as mesmas sejam formuladas para atender à exigência em energia metabolizável das aves.

Como as rações utilizadas neste experimento foram isoproteicas e seguiram as recomendações de exigências nutricionais estabelecidas para este tipo de ave (Tabela 1), era previsto que os tratamentos não interferissem na qualidade do albúmen.

Não houve diferenças $(\mathrm{P}>0,05)$ na proporção dos componentes do ovo (\% de gema, \% de casca e \% de albúmen) entre as aves que receberam ração contendo farelo de coco armazenado sem BHT (grupo controle) e aquelas alimentadas com rações em que o farelo de coco foi tratado durante o armazenamento (Tabela 4).
Segundo Grobas \& Mateos (1996), a proporção relativa de gema, casca e albúmen no ovo varia em função de diversos fatores, sobretudo pela alimentação. Considerando as diferenças na composição química de cada componente, a deficiência de determinado nutriente na ração pode, dentro de certos limites, resultar em diminuição do percentual de albúmen, gema ou casca.

Como é alto o percentual de ácido linoleico na gema, a destruição de parte deste ácido durante o processo oxidativo da fração lipídica do alimento pode acarretar redução na proporção desse componente. Contudo, Silva et al. (1990), utilizando rações contendo farelo de arroz rancificado, tratado ou não com antioxidante, na alimentação de poedeiras, não verificaram efeito na proporção de gema. Nesta pesquisa, é possível que o nível de oxidação do farelo de coco, armazenado durante 35 dias com ou sem BHT, não tenha sido suficiente para alterar o conteúdo de ácido linoleico da ração, o que proporcionou a obtenção de ovos com valores percentuais de gema semelhantes $(\mathrm{P}>0,05)$ entre as rações (Tabela 4).

A rancidez da gordura da ração pode causar sintomas carenciais de vitamina D (Leeson \& Summers, 2001), substância essencial à absorção e mobilização do cálcio no organismo das aves, prejudicando a formação da casca do ovo. Este fato parece explicar os resultados da pesquisa desenvolvida por Pita et al. (2004), que verificaram significativa redução no peso da casca de ovos quando alimentaram as aves com rações contendo alto nível de AGPI sem a adição de tocoferol. Contudo, quando estas rações foram suplementadas com o antioxidante, houve incremento no valor percentual da casca.

As rações contendo farelo de coco tratado ou não com antioxidante em diferentes tempos e armazenado por 35 dias não afetaram $(\mathrm{P}>0,05)$ a porcentagem de casca (Tabela 4$)$. Os resultados apresentados foram, provavelmente, ocasionados pela utilização de rações experimentais isonutritivas, formuladas para atender às exigências nutricionais das aves em produção, e pelo fato de o consumo de ração pelas poedeiras não ter sido influenciado pelo nível de oxidação do farelo de coco.

Tabela 4 - Unidades Haugh, porcentagem de gema, casca e albúmen e cor da gema de ovos de poedeiras alimentadas com rações contendo farelo de coco tratado ou não com BHT durante o armazenamento

\begin{tabular}{lccccccc}
\hline Variável & \multicolumn{7}{c}{ Tempo de armazenamento (dias) } \\
\cline { 2 - 6 } & Sem BHT & BHT/0 & BHT/7 & BHT/14 & BHT/21 & Média & CV (\%) \\
\hline Unidades Haugh & 88,12 & 85,58 & 85,62 & 84,80 & 87,14 & 86,25 & 3,18 \\
Gema (\%) & 24,69 & 24,72 & 24,22 & 25,26 & 24,47 & 24,67 & 8,97 \\
Casca (\%) & 8,86 & 9,09 & 9,02 & 9,16 & 8,74 & 66,35 & 2,58 \\
Albúmen (\%) & 66,44 & 66,19 & 66,76 & 65,57 & 66,79 & 8,93 & 2,33 \\
Cor da gema & 9,00 & 9,00 & 8,67 & 9,00 & 9,00 & & 2,59 \\
\hline
\end{tabular}

Médias diferem $(\mathrm{P}<0,05)$ pelo teste Dunnett. $\mathrm{CV}=$ Coeficiente de variação. 
A proporção de albúmen não variou $(\mathrm{P}>0,05)$ entre as rações (Tabela 4), o que era esperado, já que os pesos relativos da gema e da casca não diferiram entre os grupos alimentados com rações contendo farelo de coco tratado com antioxidante e aqueles que receberam rações cujo farelo não foi tratado.

A cor amarelo-laranja da gema é proporcionada por carotenoides, substâncias lipossolúveis transferidas pelos mesmos mecanismos dos lipídios aos folículos ovarianos, onde ficam armazenadas como gorduras ou lipoproteínas na gema dos ovos. A oxidação dos lipídios pode destruir estes pigmentos, causando problemas na coloração das gemas (Robey \& Shermer, 1994).

Como medida preventiva, é comum adicionar antioxidante ao alimento ou à ração o mais rápido possível (Bermudez et al., 2002). Os antioxidantes naturais, como a vitamina E, são absorvidos e transportados para o ovo (Meluzzi et al., 2000; Pita et al., 2004), protegendo-o contra a oxidação.

Apesar de Jones et al. (1986) terem constatado que o Endox, o ETQ e o BHT foram eficientes em proteger a vitamina A presente em uma ração armazenada por 30 dias em diferentes meses do ano contra o ataque dos peróxidos, Bermudez et al. (2002) não notaram efeito da adição do ETQ ao milho triturado e armazenado durante 4 semanas, uma vez que a cor das gemas dos ovos das poedeiras não diferiu entre os tratamentos.

Neste estudo, a cor da gema dos ovos das aves alimentadas com a ração contendo farelo de coco não tratado com BHT não diferiu $(\mathrm{P}>0,05)$ da obtida com as rações em que o antioxidante foi adicionado ao farelo de coco em diferentes tempos de armazenamento (Tabela 4). $\mathrm{O}$ que mais contribuiu para a obtenção destes resultados foi o fato de as rações utilizadas conterem a mesma quantidade de milho e de pigmento sintético (SunRed ${ }^{\circledR}$ ), principais ingredientes responsáveis pela coloração adequada das gemas.

\section{Conclusões}

A adição de antioxidante não foi efetiva no controle da rancidez oxidativa. A inclusão de $10 \%$ de farelo de coco armazenado durante 35 dias sem antioxidante na ração não afeta o desempenho produtivo nem a qualidade do ovo de poedeiras comerciais.

\section{Referências}

ASSOCIATION OF OFFICIAL ANALYTICAL CHEMISTS AOAC. Official methods of analysis. 15.ed. Arlington: AOAC, 1990. 1298p.
BASTOS, S.C.; FUENTES, M.F.F.; FREITAS, E.R. et al. Efeito da inclusão do farelo de coco em rações para frango de corte. Revista Ciência Agronômica, v.38, n.3, p.297-303, 2007.

BERMUDEZ, V.L.; FISCHER, G.; SIQUEIRA, E.B. et al. Efeito da utilização do etoxiquim na produção e na qualidade de ovos. In: REUNIÃO ANUAL DA SOCIEDADE BRASILEIRA DE ZOOTECNIA, 39., 2002, Recife. Anais... Recife: SBZ, 2002. (CD-ROM).

CABEL, M.C.; WALDROUP, W.; SHERMER, W.D. et al. Effects of ethoxyquin feed preservative and peroxide level on broiler performance. Poultry Science, v.67, n.12, p.1725-1730, 1988.

CORnEliUS, J.A. Coconuts: a review. Tropical Science, v.15, n.1, p.15-37, 1973.

EMPRESA BRASILEIRA DE PESQUISA E AGROPECUÁRIA EMBRAPA. Centro Nacional de Pesquisa de Suínos e Aves. Tabelas de composição química e valores energéticos de alimentos para suínos e aves. 3.ed. Concórdia: EmbrapaCNPSA, 1991. 97p. (Documentos, 19).

ENGBERG, R.M.; LAURIDSEN, C.; JENSEN, S.K.; et al. Inclusion of oxidized vegetable oil in broiler diets. Its influence on nutrient balance and on oxidative status of broilers. Poultry Science, v.75, p.1003-1011, 1996.

FISCHER, G.; BERMUDEZ, V.L.; SIQUEIRA, E.B. et al. Peroxidação em amostras de milho, protegidas ou não por etoxiquim. Ciência Animal Brasileira, v.6, n.4, p.227-232, 2005.

GROBAS, S.; MATEOS, G.G. Influencia de la nutricion sobre la composición nutricional del huevo. In: CURSO DE ESPECIALIZACIÓN FEDNA, 12., 1996, Madrid. Curso de Especialización. Madrid: FEDNA, 1996. p.219-244.

GROBAS, S.; MÉNDEZ, J.; LÁZARO, R. et al. Influence of source and percentage of fat added to diet on performance and fatty acid composition of egg yolks of two strains of laying hens. Poultry Science, v.80, p.1171-1179, 2001.

HUSSEIN, A.S.; KRATZER, F.H. Effect of rancidity on the feeding value of rice bran for chickens. Poultry Science, v.61, p.2450-2455, 1982.

JONES, F.T.; WARD, J.B.; BREWER, C.E. Antioxidant use in broiler feeds. Poultry Science, v.65, p.779-781, 1986.

LEESON, S. Programas de alimentación para ponedoras y broilers. In: CURSO DE ESPECIALIZACIÓN FEDNA, 12., 1996, Madrid. Curso de Especialización. Madrid: FEDNA, 1996. p.201-216.

LEESON, S.; SUMMERS, J.D. Nutrition of the chicken. 4.ed. Canada: University Books, 2001. 591p.

LIMA NETO, R.C.; SOUZA, C.J.; COSTA, F.G.P. et al. Desempenho de poedeiras semipesadas submetidas a dietas com diferentes níveis de óleos de soja e canola. In: REUNIÃO ANUAL DA SOCIEDADE BRASILEIRA DE ZOOTECNIA, 44., 2007, Jaboticabal. Anais... Jaboticabal: SBZ, 2007. (CD-ROM).

LIMA, R.C.; FUENTES, M.F.F.; FREITAS, E.R.; et al. Farelo de coco na ração de poedeiras comerciais: digestibilidade dos nutrientes, desempenho e qualidade dos ovos. Revista Brasileira de Zootecnia, v.5, p.1340-1346, 2007.

MANO, S.; FANTICELLI, R.; MORAES, I.A. Qualidade dos ovos e de seus derivados. Avicultura Industrial, n.6, p.48-52, 2007.

MCGEACHIN, R.B.; SRINIVASAN, L.J.; BAILEY, C.A. Comparison of the effectiveness of two antioxidants in a broiler type diet. Journal Applied Poultry Research, v.1, p.355-359, 1992.

MELUZZI, A.; SIRRI, F.; MANFREDA, G. et al. Effects of dietary vitamin $E$ on the quality of table eggs enriched with n-3 longchain fatty acids. Poultry Science, v.79, p.539-545, 2000.

PANIGRAHI, S. Effects on egg production of including high residual lipid copra meal in laying hen diets. British Poultry Science, v.30, p.305-312, 1989.

PITA, M.C.G.; PIBER NETO, E.; NAKAOKA, L.M. et al. Efeito da adição de ácidos graxos insaturados e de vitamina $\mathrm{E}$ à dieta de galinhas e seu reflexo na composição lipídica e incorporação de $\alpha$-tocoferol na gema do ovo. Brazilian Journal of Veterinary Research and Animal Science, v.41, p.25-31, 2004.

RACANICCI, A.M.C.; MENTEN, J.F.M.; IAFIGLIOLA, M.C. et al. Efeito da adição do antioxidante BHT e do armazenamento sobre a qualidade da farinha de carne e ossos para frangos de corte. Revista Brasileira de Ciência Avícola, v.2, n.2, p.155-161, 2000. 
ROBEY, W.; SHERMER, W. The damaging effects of oxidation. Feed Mix, v.2, n.5, p.22-26, 1994.

ROSTAGNO, H.S.; ALBINO, L.F.T.; DONZELE, J.L. et al. Tabelas brasileiras para aves e suínos: composição de alimentos e exigências nutricionais. Viçosa, MG: UFV/Departamento de Zootecnia, 2000. 141p.

SILVA, D.J.; QUEIROZ, A.C. Análise de alimentos: métodos químicos e biológicos. 3.ed. Viçosa, MG: Universidade Federal de Viçosa, 2002. 165p.
SILVA, Y.L.; PEIXOTO, R.R.; PEIXOTO, C.R. Efeito da rancidez no valor nutricional de farelo de arroz com alto teor de gordura para poedeiras. Revista da Sociedade Brasileira de Zootecnia, v.19, n.1, p.23-30, 1990.

STATISTICAL ANALYSIS SYSTEM - SAS. SAS user's guid: Statistics. Version 8. 2.ed. Carry: SAS Institute, 2000. (CD-ROM). WANG, S.Y.; BOTTJE, W.; MAYNARD, P. et al. Effects of Santoquim ${ }^{\circledR}$ and oxidized fat on liver and intestinal glutatione in broilers. Poultry Science, v.76, p.961-967, 1997. 